\title{
Uso do Scrum como método para otimização na elaboração de projetos
}

\author{
Use of Scrum as a method for optimization in project design \\ Uso de Scrum como método de optimización en la preparación de proyectos
}

Recebido: 16/07/2021 | Revisado: 20/07/2021 | Aceito: 21/07/2021 | Publicado: 29/07/2021

\author{
Almiro Midons Bastos \\ ORCID: https://orcid.org/0000-0001-5242-0881 \\ Prefeitura Municipal de Santana, Brasil \\ E-mail: midonsbastos@gmail.com \\ Argemiro Midonês Bastos \\ ORCID: https://orcid.org/0000-0001-5411-647X \\ Instituto Federal de Educação, Ciência e Tecnologia do Amapá, Brasil \\ E-mail: argemiro.bastos@ifap.edu.br
}

\begin{abstract}
Resumo
$\mathrm{Na}$ administração pública, a gestão de projetos de interesse municipal deve buscar a otimização de recursos humanos para possibilitar redução de tempo nas etapas de avaliação e acompanhamento das atividades dos projetos. O objetivo deste artigo é apresentar os benefícios que foram adquiridos com a implantação de uma adaptação do framework Scrum no setor de Gerência de Projetos (GP) da Secretaria Municipal de Obras Públicas e Serviços Urbanos SEMOP, no município de Santana (AP). A partir da implantação desta metodologia foi possível padronizar a elaboração de projetos de arquitetura e seus complementares e ao mesmo tempo gerenciá-los, indicando que o framework Scrum não está restrito apenas projetos de engenharia de software e que quando bem empregado melhora o relacionamento da equipe, facilita o acompanhamento e desenvolvimento de qualquer projeto, diminuindo o desperdício de materiais e o tempo de elaboração. Além de proporcionar uma constante manutenção nas boas práticas da organização e disseminando o conhecimento tático dos envolvidos em equipes participantes de projetos. Durante o tempo de análise da ferramenta houve otimização, em média, de $66 \%$ no tempo destinado anteriormente às atividades de avaliação e aprovação de projetos na SEMOP. Apesar dos resultados positivos quanto à economicidade de recursos, ainda se faz necessária a contratação de novos servidores e aquisição de equipamentos que os auxiliem na execução do seu trabalho diário na elaboração de projetos.
\end{abstract}

Palavras-chave: Gestão; Métodos ágeis; Otimização.

\begin{abstract}
In public administration, the management of projects of municipal interest must seek the optimization of human resources to enable time reduction in the stages of evaluation and monitoring of project activities. The purpose of this article is to present the benefits that were acquired with the implementation of an adaptation of the Scrum framework in the Project Management (PM) sector of the Municipal Public Works and Urban Services - SEMOP, in the county of Santana (AP). As a result, it was possible to standardize the elaboration of architectural projects and their complementary ones and, at the same time, manage them, indicating that the Scrum framework is not restricted to software engineering projects. When well used, this tool improves relationship teams, facilitates monitoring and development of any project, reduces materials waste, and elaborates time, besides promoting constant maintenance of the organization's good practices and disseminating the tactical knowledge of those involved in teams participating projects. During the tool analysis time, an average of $66 \%$ was optimized in the time previously allocated to the evaluation and approval activities of projects at SEMOP. However, despite the positive results regarding the economy of resources, it is still necessary to hire new servers and purchase equipment to help them perform their daily work to prepare projects.
\end{abstract}

Keywords: Agile methods; Management; Optimization.

\section{Resumen}

En la administración pública, la gestión de proyectos de interés municipal debe buscar la optimización de los recursos humanos para permitir la reducción de tiempos en las etapas de evaluación y seguimiento de las actividades del proyecto. El propósito de este artículo es presentar los beneficios que se adquirieron con la implementación de una adecuación del marco Scrum en el sector Project Management (PM) de la Obra Pública Municipal y Servicios Urbanos - SEMOP, en el municipio de Santana (AP). A partir de la implementación de esta metodología se logró estandarizar la elaboración de proyectos arquitectónicos y sus complementarios y, al mismo tiempo, gestionarlos, indicando que el framework Scrum no se restringe a proyectos de ingeniería de software y que bien utilizada mejora la relación de equipo, facilita el seguimiento y desarrollo de cualquier proyecto, reduciendo el desperdicio de materiales y tiempo de preparación. Además de brindar un mantenimiento constante de las buenas prácticas de la organización y 
difundir el conocimiento táctico de los involucrados en los equipos que participan en los proyectos. Durante el tiempo de análisis de la herramienta, se optimizó en promedio un $66 \%$ en el tiempo previamente asignado a las actividades de evaluación y aprobación de proyectos en la SEMOP. A pesar de los resultados positivos en cuanto a economía de recursos, aún es necesario contratar nuevos servidores y adquirir equipos que les ayuden a realizar su trabajo diario en la preparación de proyectos.

Palabras clave: Gestión; Métodos ágiles; Optimización.

\section{Introdução}

No Brasil os métodos ágeis têm despertado interesse na comunidade acadêmica e equipes de desenvolvimento de projetos, sejam eles de software ou não, (Silva et al., 2013; Silva \& Neto, 2015; Mendonça et al., 2018; Stopa \& Rachid, 2019; Camargo, et al., 2001). O framework Scrum é um método bastante utilizado, que visa desenvolver, entregar e manter produtos complexos, no qual as pessoas podem tratar e resolver problemas complexos e adaptativos, enquanto entregam produtos com o mais alto valor possível (Sutherland \& Schwaber, 2017). Segundo a PMI ${ }^{\circledR}$ (PMI, 2017) cerca de 70 milhões de pessoas nos mais diversos campos e organizações estão fazendo uso diretamente da metodologia ágeis, no desenvolvimento de projetos.

Os projetos de arquitetura e engenharia possuem a vantagem de reduzir custos e o tempo de execução de uma obra, pois especificam todos os materiais necessários que deverão ser utilizados na implantação de um projeto, fornecem desenhos que mostram o passo a passo para a execução da obra, além de determinar o tempo que será utilizado para conclusão do empreendimento, evitando desta forma o desperdício de materiais e tempo de execução (Mendonça et al., 2018). No município de Santana, no estado do Amapá, o setor de Gerência de projetos (GP) funciona na Secretaria Municipal de Obras Públicas e Serviços Urbanos (SEMOP), sendo o órgão responsável pela elaboração de projetos de arquitetura e engenharia. A partir de um estudo de caso realizado na SEMOP, foram observados pontos negativos que oneravam as elaborações de projetos por ela desenvolvidos, tais como: desarticulação entre os técnicos responsáveis pela formatação dos projetos, múltiplas impressões do projeto após correção de inconsistências, retorno dos projetos dos órgãos fiscalizadores para correções técnicas e excessivo gasto de tempo nas fases de proposição e elaboração dos projetos.

O objetivo deste artigo é apresentar os benefícios adquiridos a partir do uso de uma adaptação do Framework Scrum na GP para uma boa prática na elaboração de projetos e gerenciamento, e sua futura implantação em definitivo com montagem de pequenas equipes e uma maior comunicação entre os envolvidos. Este artigo foi estruturado em 5 partes, na introdução identificaremos a problemática que apontou a necessidade de se melhorar o processo de elaboração de projetos, na segunda apresentaremos o setor GP e suas atribuições, na terceira falaremos um pouco sobre métodos ágeis e o porquê da sua escolha, na quarta apresentaremos a metodologia utilizada e por fim falaremos da adaptação do Framework Scrum e as consideraç̃oes finais.

\section{Setor gerência de projetos da SEMOP}

A GP é um setor da SEMOP, onde os projetos são elaborados. Criada em 17 de maio de 2005 através da lei 696/2005PMS e alterada pelo decreto 348/2017-PMS de 13 de janeiro de 2017, tem a finalidade de elaborar e gerir os projetos nas áreas de infraestrutura e social, captando recursos públicos e privados, nas esferas estaduais, federais e/ou internacionais, bem como assessorar as unidades administrativas da prefeitura municipal na elaboração e gestão de seus projetos.

A SEMOP é responsável pelo gerenciamento, direto e indireto dos projetos no município de Santana, sejam eles provenientes de emendas parlamentares, convênios com ministérios, parceria entre o estado ou administração direta, no que diz respeito à captação de recursos, elaboração de projetos, fiscalização dos projetos e execução destes. Na Figura 1, observa-se quais os setores que compõe a SEMOP conforme o decreto 348/2017, destacando o setor que foi diretamente afetado com a adaptação. 
Figura 1 - Organograma da Secretaria Municipal de Obras Públicas e Serviços Urbanos (SEMOP).

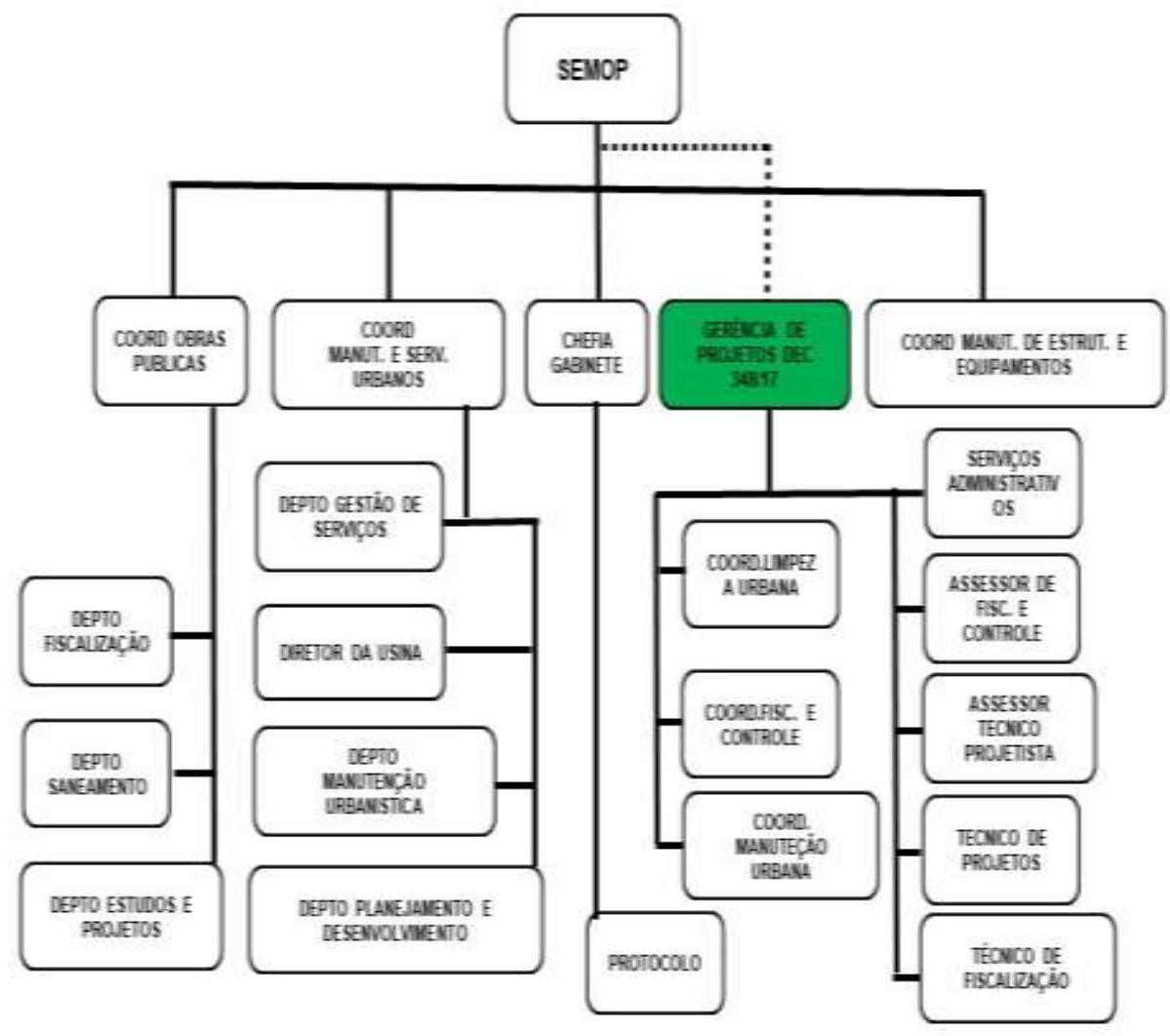

Fonte: Autores (2019).

Atualmente a SEMOP é composta por uma equipe multidisciplinar de trinta e sete (37) técnicos, que exercem suas atividades profissionais dentro de sua competência ou responsabilidade, devidamente registrados nos conselhos de classe, conforme apresentado no Quadro 1.

Quadro 1 - Composição do corpo técnico de profissionais da Gerência de projetos (GP) e suas reponsabilidades.

\begin{tabular}{|c|c|c|}
\hline Profissional & Quantidade & Responsabilidades \\
\hline Topografo & 01 & Realizar o levantamento topográfico da área onde será implantado o projeto \\
\hline Arquiteto & 05 & $\begin{array}{l}\text { Elaborar o projeto arquitetônico e urbanístico que seja funcional, gerenciar a equipe técnica, } \\
\text { mitigar as dificuldades da equipe, fornecer o maior número de informações para execução do } \\
\text { projeto. }\end{array}$ \\
\hline Engenheiro Civil & 07 & $\begin{array}{l}\text { Elaborar projeto estrutural, elaborar o custo real do projeto através do orçamento, definir que } \\
\text { tipo de material será utilizado no projeto }\end{array}$ \\
\hline $\begin{array}{l}\text { Engenheiro } \\
\text { Ambiental/Sanitarista }\end{array}$ & 01 & $\begin{array}{l}\text { Elaborar projeto de drenagem, hidrossanitário, água fria e estudos para retirada de licença } \\
\text { ambiental. }\end{array}$ \\
\hline Engenheiro Eletricista & 01 & Elaborar projeto elétrico e Sistemas de Proteção contra Descargas Atmosféricas (SPDA) \\
\hline Cadista/Desenhista & 10 & $\begin{array}{l}\text { Realizar levantamento fotográfico e técnico in loco; realizar desenho técnico conforme } \\
\text { solicitação do arquiteto }\end{array}$ \\
\hline $\begin{array}{l}\text { Técnico Segurança no } \\
\text { Trabalho }\end{array}$ & 02 & $\begin{array}{l}\text { Traçar e implantar meios de proteger o colaborador de possíveis acidentes de trabalho. } \\
\text { Protegendo a saúde dos funcionários, ajudando na produtividade de uma empresa. }\end{array}$ \\
\hline $\begin{array}{l}\text { Assistente } \\
\text { Administrativo }\end{array}$ & 06 & $\begin{array}{l}\text { Reunir ou providenciar todos os documentos que um projeto necessita tais como: documento } \\
\text { do terreno, anuência da Companhia de Eletricidade do Amapá (CEA), Companhia de Água e } \\
\text { Esgoto do Amapá (CAESA), vigilância sanitária, corpo de bombeiros, licença do Instituto } \\
\text { do Meio Ambiente e de Ordenamento Territorial do Amapá (IMAP) ou Secretaria Municipal } \\
\text { de Desenvolvimento Urbano e Habitação (SEMDUH), formata os documentos entregues } \\
\text { pelos técnicos, montar pastas para encaminhar ao prefeito ou órgão concedente como } \\
\text { ministério ou governo do estado. }\end{array}$ \\
\hline
\end{tabular}




\begin{tabular}{|l|c|l|}
\hline Turismóloga & 01 & $\begin{array}{l}\text { É responsável por pesquisar, planejar, organizar, a promoção e divulgação de atividades } \\
\text { ligadas ao turismo. }\end{array}$ \\
\hline Técnico em edificação & 03 & $\begin{array}{l}\text { Desenhar projetos de projetos, especificar os materiais necessários à obra, defini as equipes } \\
\text { de trabalho e elaborar orçamentos e cronogramas de projetos elétricos, hidrossanitários, de } \\
\text { gás, de estruturas de concreto ou metálicas etc., sempre obedecendo às normas técnicas. }\end{array}$ \\
\hline
\end{tabular}

Fonte: Autores.

A partir do histórico de projetos já executados pela GP, ao longo dos últimos oito anos (2010 - 2018), e considerando as atividades executadas pela equipe técnica, construiu-se um quadro (Quadro 2) do tempo médio necessário para execução das ações inerentes ao desenvolvimento dos projetos.

Quadro 2 - Atividades desenvolvidas na Gerência de Projetos e o tempo gasto na execução.

\begin{tabular}{|c|c|c|c|}
\hline Atividade & Tempo (dias) & $\begin{array}{c}\text { Média } \\
\text { (dias) }\end{array}$ & Ação \\
\hline $\begin{array}{l}\text { Levantamento da área de } \\
\text { implantação }\end{array}$ & 1 a 2 & 1,5 & $\begin{array}{l}\text { Avaliar se a área disponibilizada para o projeto é } \\
\text { apropriada, para este tipo de empreendimento }\end{array}$ \\
\hline $\begin{array}{l}\text { Aquisição de documentação que } \\
\text { deverá constar no projeto }\end{array}$ & $(15 \text { a } 45)^{*}$ & 30 & $\begin{array}{l}\text { Todos os projetos devem apresentar uma relação de } \\
\text { documentos dos órgãos envolvidos. }\end{array}$ \\
\hline $\begin{array}{l}\text { Elaboração de } \begin{array}{r}\text { projetos } \\
\text { (topografia, } \\
\text { hidrossanitário, elétrico etc. }\end{array} \\
\text { hida, }\end{array}$ & $(30 \text { a } 70)^{*}$ & 50 & $\begin{array}{l}\text { Os projetos devem atender às necessidades pontuadas } \\
\text { pelo requisitante do projeto }\end{array}$ \\
\hline Anuência dos órgãos externos & $(5 \text { a } 60)^{*}$ & 32,5 & $\begin{array}{l}\text { Os projetos devem atender as normativas estabelecidas } \\
\text { pela legislação vigente. }\end{array}$ \\
\hline Aprovação do órgão concedente & $(30 \text { a } 90)^{*}$ & 60 & Este é responsável pela aprovação final do projeto \\
\hline Duração & $(81 \text { a } 267)^{*}$ & 174 & Tempo gasto para elaboração de projeto \\
\hline
\end{tabular}

(*) Serão impactados com a implantação da proposta, reduzindo o seu tempo. Fonte: Autores.

\section{Metodologia ágeis com ênfase no Scrum}

As Metodologias Ágeis foram criadas na indústria de Tecnologia da Informação para resolver problemas comuns a quase toda organização que precisa gerenciar projetos, que apresentavam etapas de produção muito longas e sem entregas definidas; falta de clareza e comunicação entre os times; desalinhamento entre equipe e cliente e outros. Foram rapidamente adotadas em outros mercados além dos de tecnologia da informação (Conboy, 2009; Silva et al., 2013).

Todo projeto precisa ter um início e um fim bem definidos, porém é comum que sua execução se estenda por períodos de mais de anos - durante os quais muitos fatores podem concorrer para o atraso na execução da obra (Bergamaschi \& Zuchi, 2018). Observou-se que era preciso desenvolver métodos inteligentes e eficientes que conseguissem contornar esses problemas e que pudessem simplificar a forma como os projetos eram executados - gerando impactos positivos em sua finalização.

Em oposição aos modelos tradicionais, as metodologias ágeis propõem ciclos de desenvolvimento curtos, com entregas bem definidas e foco na melhoria contínua dos processos e alinhamento da equipe conforme o manifesto ágil. Com isso, passou a ser mais simples identificar erros e falhas durante a execução dos projetos e as pessoas envolvidas ganharam mais flexibilidade e facilidade para fazer adaptações e evitar que determinados problemas afetassem o seu resultado. Como exemplos de métodos ágeis, pode-se citar o Scrum, Kanban, eXtreme Programming (XP), Feature Driven Development (FDD), Lean (Silva \& Neto, 2014).

O Scrum foi criado por Jeff Sutherland e Ken Schwaber, e foi escolhido por ser o que melhor se identificou ao desenvolvimento da proposta; este método é uma metodologia ágil para gestão e planejamento, porém vale ressaltar que não está restrito somente a projetos de software. Conforme Cruz (2018), trabalha com projetos complexos, que são subdivididos 
em etapas ou tarefas menores, através de controle de inspeção, adaptação e visibilidade de requisitos de um processo empírico fazendo uso de uma série de regras e práticas, onde controle não significa controle para criar o que foi previsto e sim controlar o processo para orientar o trabalho em direção a um produto com o maior valor agregado possível.

No Scrum, os projetos são divididos em ciclos chamados de Sprints, que ocorrerem entre uma semana e um mês, precedido por uma reunião de planejamento, onde tarefas são identificadas e um compromisso para o objetivo do Sprint é definido, seguido por uma reunião de revisão ou de retrospectiva, onde o progresso é revisto e lições para os próximos sprints são identificadas (Figura 2). Todas as sprints são postas em Product Backlog, que nada mais é do que uma lista de itens priorizados a serem desenvolvidos para um projeto. O Product Backlog é mantido pelo Product Owner e é uma lista de requisitos que tipicamente vêm do cliente, depois de observar as suas necessidades. O Sprint representa um Time Box dentro do qual um conjunto de atividades deve ser executado. Ele apresenta papéis principais que são: o Product Owner, o Scrum Master e o Scrum Team (Figura 3).

Figura 2 - Estrutura do Scrum.

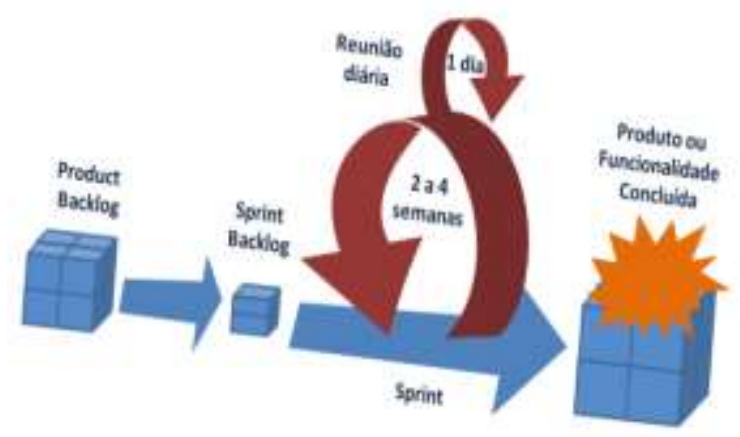

Fonte: https://www.projectbuilder.com.br/blog/quais-sao-os-principais-tipos-de-metodos-ageis/.

Figura 3 - Papeis no Scrum.

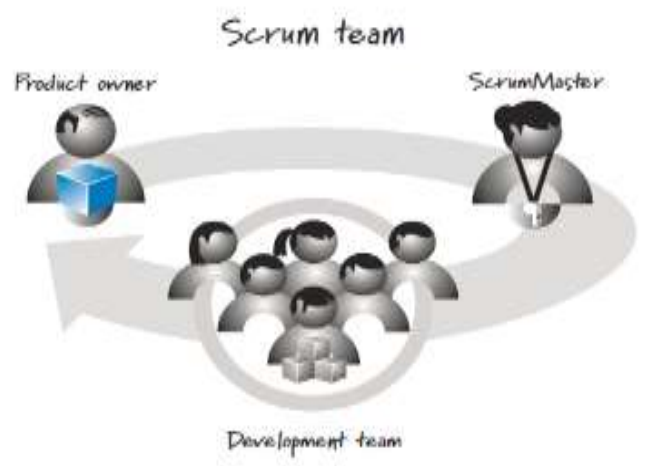

Fonte: https://www.projectbuilder.com.br/blog/quais-sao-os-principais-tipos-de-metodos-ageis/.

Na metodologia Scrum, não existe posições ou cargos hierárquicos e sim atores que desempenham os seus papeis com as suas respectivas atribuições, de forma bem definida. No Quadro 3 é apresentado um resumo do papel que cada ator assume nesta metodologia. 
Quadro 3 - Papeis desempenhados pelos atores na metodologia Scrum.

\begin{tabular}{|c|c|c|}
\hline Ator & Papel & Atribuições \\
\hline $\begin{array}{l}\text { Product } \\
\text { Owner }\end{array}$ & Representante & $\begin{array}{l}\text { Definir os requisitos do produto, a data de release e o que deve conter nela. } \\
\text { É responsável pelo retorno financeiro (ROI) do produto. } \\
\text { Prioriza os requisitos de acordo com o seu valor de mercado. } \\
\text { Pode mudar os requisitos e prioridades a cada Sprint. } \\
\text { Aceita ou rejeita o resultado de cada Sprint. }\end{array}$ \\
\hline $\begin{array}{l}\text { Scrum } \\
\text { Master }\end{array}$ & Chefe da equipe & $\begin{array}{l}\text { Garantir que o time esteja totalmente funcional e produtivo. } \\
\text { Facilitar a colaboração entre as funções e áreas e eliminar os impedimentos do } \\
\text { time. } \\
\text { Proteger o time de interferências externas. } \\
\text { Garantir que o processo está sendo acompanhado. Participando das reuniões } \\
\text { diárias, revisão da Sprint, e planejamento. }\end{array}$ \\
\hline Scrum Team & $\begin{array}{l}\text { Equipe Multifuncional } \\
\text { formada geralmente por } 5 \text { a } 9 \\
\text { membros }\end{array}$ & $\begin{array}{l}\text { Prioriza o que irá ser executado durante o Sprint, com o direito de realizar o } \\
\text { que quiser dentro de um Sprint }\end{array}$ \\
\hline
\end{tabular}

Fonte: Autores.

\section{Metodologia}

O estudo possui natureza aplicada, pois gerou conhecimentos necessários à apresentação de uma proposta que visa solucionar o problema pesquisado neste trabalho, como propõem Prodanov \& Freitas (2013). Optou-se por uma abordagem qualitativa, que descrita por Oliveira $(2011$, p. 28), “[...] é um processo de reflexão e análise da realidade através da utilização de métodos e técnicas para compreensão detalhada do objeto de estudo em seu contexto ou segundo sua estrutura". Quanto aos fins da pesquisa, esta foi descritiva e cronológica, pois desde a etapa da identificação da equipe até a entrega dos projetos fezse uso da observação dos fatos, registros, organização e análise dos dados; características de uma pesquisa descritiva como afirmam Prodanov \& Freitas (2013). Do ponto de vista dos procedimentos técnicos, trata-se de um estudo de caso, realizado na GP da SEMOP, órgão da administração municipal de Santana (AP), no período de agosto de 2018 a dezembro de 2019.

O estudo foi realizado, através de interação com os funcionários do setor da GP, utilizando-se de entrevistas e conversas programadas, acessando dados, documentos e outros materiais da secretaria. Tendo como objetivo identificar as práticas formais da organização, assim como opiniões e atitudes dos sujeitos envolvidos na elaboração de projetos de arquitetura e seus complementares. A partir do acesso aos dados, documentos e outros materiais da organização, pode-se identificar os procedimentos formais da organização, assim como o tempo de duração de cada atividade, e o responsável em cada etapa de elaboração dos projetos. Assim, foi possível identificar problemas nos processos e sugerir melhorias.

O primeiro passo foi identificar os problemas que as equipes da GP encontravam, e em alguns casos cometiam durante a elaboração de projetos, dentre eles podemos citar: a falta de informações mínimas para a elaboração, como por exemplo: a equipe não tinha em seu time um representante da secretaria que seria contemplada pelo projeto. Este profissional deveria apresentar a necessidade de se implantar o projeto solicitado, informar que ambientes/salas deveriam constar no projeto, ou seja, definir o plano de necessidades e ao mesmo tempo esclarecer as dúvidas que surgiam no decorrer da elaboração, dúvidas como, qual o valor disponível para o projeto, pois foi também observado em alguns casos que, a equipe elaborava um macroprojeto e só depois ficava sabendo que o valor disponível era bastante inferior ao projeto elaborado.

Outro problema encontrado, foi o tamanho do time, que era grande, dificultando a troca de informações entre eles, pois os membros do time não sabiam o que cada um estava fazendo e qual o status de cronograma das tarefas. Também foi observado que fases estavam sendo negligenciadas (postergadas), por exemplo, na elaboração de um projeto, o primeiro passo a ser tomado é fazer uma visita in loco para se realizar um levantamento topográfico e conhecer o terreno, para só depois elaborar o projeto arquitetônico e os seus sucessivos, algo que não era realizado! 


\section{Adaptação da metodologia Scrum no setor Gerência de Projetos}

A proposta de uso da metodologia Scrum foi apresentada aos gestores da SEMOP no início do ano de 2019 e aplicada a cinco projetos demandados pela Prefeitura Municipal de Santana, a partir da captação de recursos de emendas parlamentares.

As primeiras medidas tomadas foram: criar no servidor da GP uma pasta compartilhada com informações sobre os projetos e padronizar o processo de elaboração de projeto, delegando tarefas de forma organizada, pois os projetos são uma forma de planejamento, e neles é mais fácil prevermos problemas e custos adicionais de materiais e de mão de obra quando bem-feitos e pensados. Isto é importante porque é a GP que desenvolve projetos para todas as secretarias que compõem o organograma da prefeitura, para atender os anseios da população santanense, ou seja, é responsável por apresentar todas as melhorias que serão desenvolvidas no município.

Ficou definido que o processo terá o seu início quando a SEMOP for provocada, mediante documento que solicite a melhoria de um prédio existente ou uma nova construção. Todas as solicitações, deverão, obrigatoriamente, passarem pela GP. A gerente recebe as solicitações e as organiza em uma lista. Cada item da lista é analisado pelos arquitetos da equipe técnica. O arquiteto verifica a relevância do projeto e o impacto que irá causar, se implantado. É o arquiteto quem verifica se o projeto é viável ou não, se a implantação está de acordo com a legislação vigente. Com base nas análises realizadas, o arquiteto decide se a solicitação pode ser atendida. Caso não seja, o arquiteto informa à gerente de projetos, para que entre em contato com o requisitante e informe os motivos da recusa. Caso seja aceita, o arquiteto e o representante pela solicitação definem que ambientes/salas/cômodos o projeto deverá conter.

Definido esses aspectos, o arquiteto reúne com a equipe técnica para eventuais dúvidas, caso surjam novas dúvidas no decorrer da elaboração, ele solicita maiores informações do representante da secretaria que será beneficiada com a implantação do projeto. O arquiteto estima o tempo para o desenvolvimento com base no seu grau de conhecimento e da equipe e pelo nível de dificuldade da elaboração. Este também pode delegar as tarefas aos técnicos integrantes da equipe. Cada tarefa é delegada a um respectivo técnico. Nesta etapa, o técnico analisa tudo o que lhe foi apresentado e pode sanar eventuais dúvidas que possam comprometer o desenvolvimento do trabalho. Apresentadas as respectivas demandas, os técnicos iniciam os seus trabalhos. Finalizada a tarefa, o arquiteto verifica se tudo que foi solicitado foi executado corretamente.

Com a tarefas realizadas e verificadas, o próximo passo é a aprovação, do responsável pela solicitação, verificando se o projeto está de acordo com o que foi realmente solicitado. Após todas as tarefas concluídas, é entregue um documento denominado aprovação de pré-projeto, no qual o responsável pela solicitação, dá ciência que tudo que foi solicitado foi atendido e assina. Outro ponto positivo alcançado foi que agora novos membros que venham a entrar na GP podem passar por um curso de capacitação algo que anteriormente não existia, esta capacitação tem duração 15 (quinze) a 20 (vinte) dias e pode ser ministrada por qualquer um dos arquitetos.

A Figura 4, apresenta o fluxograma do processo de elaboração de projetos, a partir da implantação do Scrum na GP. 
Figura 4 - Fluxograma de elaboração de projeto.

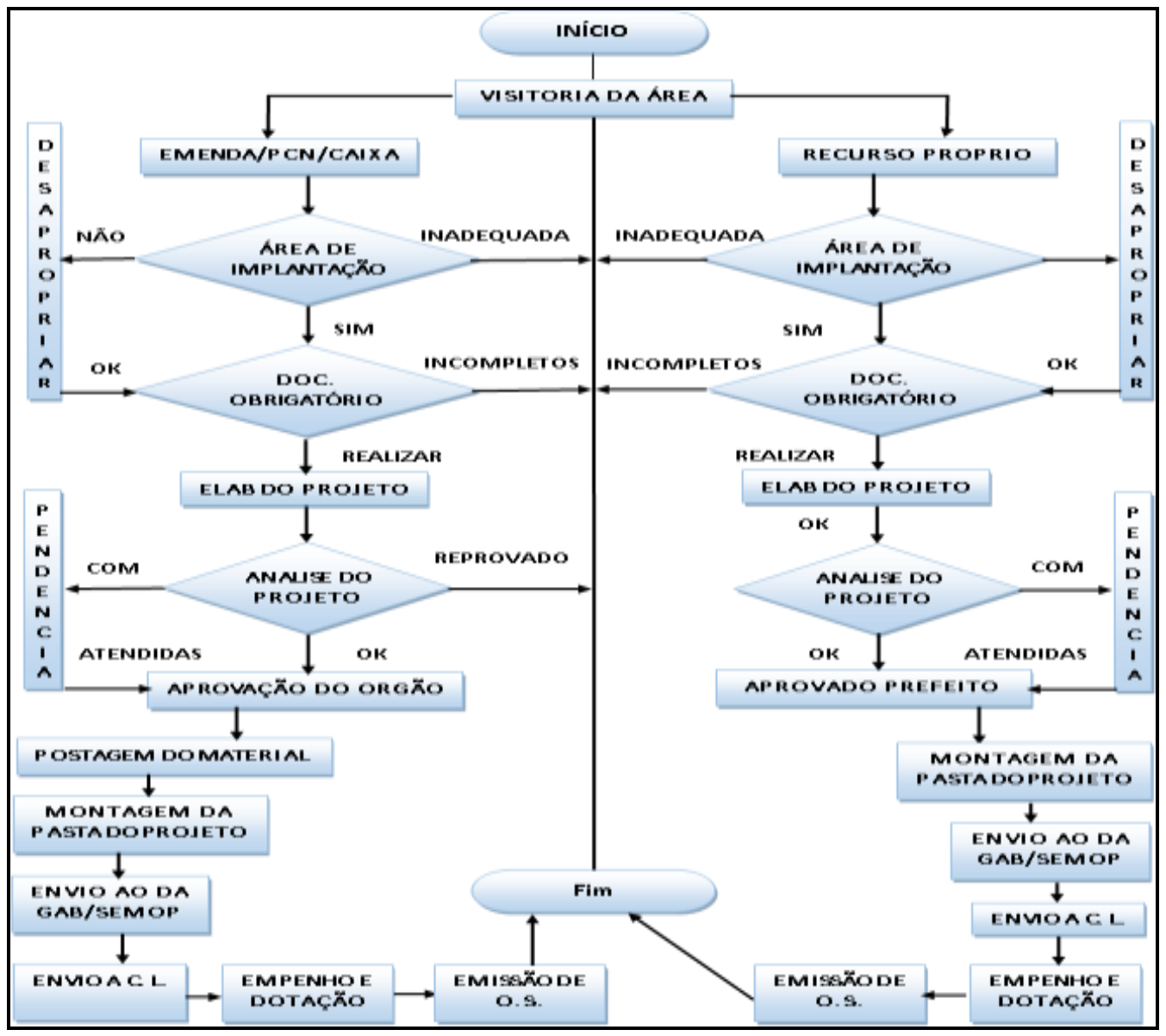

Fonte: Autores.

Diante de tudo que foi exposto e da cooperação que começou a existir entre o representante da secretaria e os arquitetos, apontando todos os anseios da comunidade santanense e tendo em vista que "o modelo" antes utilizado na elaboração de projetos foi possível montar uma nova equipe. Dessa forma, por ser um projeto relativamente novo, assim como uma equipe nova com um padrão pré-definido de desenvolvimento, espera-se que seja mais fácil realizar a implantação do Scrum. No Quadro 4, podemos verificar como ficarão definidas as equipes e suas responsabilidades no modelo adaptável do Scrum.

Quadro 4 - Equipe técnica formada com a implantação da adaptação do Scrum.

\begin{tabular}{|l|l|}
\hline \multicolumn{1}{|c|}{ Função } & \multicolumn{1}{c|}{ Papel } \\
\hline Representante da secretaria/gerente & Product Owner \\
\hline Arquiteto e urbanista & Scrum Master \\
\hline Cadista/desenhista & Scrum Team \\
\hline Engenheiro civil & Scrum Team \\
\hline Engenheiro sanitarista/ambiental & Scrum Team \\
\hline Engenheiro eletricista & Scrum Team \\
\hline Topografo & Scrum Team \\
\hline Assistente administrativo & Scrum Team \\
\hline
\end{tabular}

Fonte: Autores. 


\section{Resultados e Discussão}

Considerando o aumento de demanda dos setores de gerenciamentos de projetos no serviço público e as ferramentas utilizadas pela gestão, o gerenciamento de projeto caracteriza-se por práticas ainda tradicionais com observações de métodos pouco sustentáveis, centralização administrativa e burocracia excessiva (Geraldi, Maylor \& Williams, 2011), fomentando problemas nos processos comunicativos e na gestão da qualidade (Bomfin, Nunes \& Hastenreiter, 2012), gerando riscos e incertezas, dessa forma, concluem os autores, não são adequadas a esse novo ambiente de mudanças e dinamicidade exigida. A proposição e possível implantação definitiva da metodologia Scrum na GP fundamenta-se como estrutura auxiliadora na elaboração de projetos, evidenciando ser esta uma ferramenta de gerenciamento de recursos humanos e materiais. Observamos que durante o tempo em que foi implantado a adaptação do framework houve um ganho considerável de tempo em quase todas as fases da elaboração de projetos.

$\mathrm{Na}$ atividade de levantamento da área de implantação não houve redução do tempo de execução, no entanto é importante destacar que com a possibilidade de inserir arquivos de imagem georreferenciadas, vídeos do local e dados do levantamento topográfico realizado, houve impacto positivo na qualidade e tempo de execução das atividades subsequentes.

A aquisição de documentação que deverá constar no projeto que antes possuía tempo de execução médio de 30 dias, nesta metodologia passou a ser de apenas 10 dias. Houve, portanto, uma diminuição de tempo superior a $60 \%$. A documentação antes centralizada com um único técnico, agora é compartilhada com vários colaboradores. A partir do repositório criado na pasta compartilhada, a equipe tem acesso à legislação pertinente a cada projeto e um check list da documentação exigida pelos órgãos fiscalizadores contribui para o uso racional de recursos materiais, pois minimiza a duplicação de documentos com eventuais correções que pudessem inviabilizar ou postergar a aprovação do projeto pelos órgãos competentes. Além disso, a metodologia auxilia na efetividade do projeto básico para que atenda a legislação atual quanto "a viabilidade técnica e o adequado tratamento do impacto ambiental do empreendimento, e que possibilite a avaliação do custo da obra e a definição dos métodos e do prazo de execução (Brasil, 1993).

Mendonça et al. (2018) ao aplicarem a metodologia Scrum em atividades da engenharia civil, identificaram que a falta de gerenciamento adequado era motivo de desperdício de material. Neste estudo, os projetos arquitetônicos, hidrossanitário e elétrico eram acessíveis não só ao engenheiro é arquiteto, mas a toda equipe técnica. Desse modo, as eventuais correções no projeto poderiam ser discutidas em grupo e, às vezes, até remotamente, o que economizou o tempo de avaliação in loco dos arquitetos é administradores. Houve uma redução de 57\% no tempo gasto nesta atividade.

Os processos burocráticos como documentações a serem entregues, considerando sua importância para a aprovação dos projetos, receberam da equipe mais atenção a partir de uma divisão de tarefas e foco na interação e colaboração, como sugerido por Stopa \& Rachid (2019). Considerando a efetividade das fases anteriores, erros ou inconsistências comuns aos projetos quando submetidos a órgãos externos diminuiu. $\mathrm{O}$ tempo necessário para a anuência destes projetos junto ao Conselho Regional de Arquitetura e Agronomia (CREA) passou de 32 para 10 dias, em média, possibilitando uma economia de tempo da ordem de $75 \%$. Isto é extremamente importante para a gestão porque a diminuição do tempo empregado no desenvolvimento do projeto vai repercutir no gasto financeiro que a secretaria terá com essas equipes, além de possibilitar que a mesma equipe possa desenvolver concomitantemente vários projetos sem que haja uma sobrecarga de tarefas para os integrantes.

Após o envio dos projetos da GP aos órgãos concedentes, cabe a estes avaliar os aspectos técnicos e jurídicos dos projetos e de seus respectivos planos de trabalho. Esta análise que antes do uso da metodologia Scrum levava em média 60 dias, foi reduzida para 20 dias com a aplicação da metodologia. Medeiros (2013), ao comentar sobre o Princípio da Eficiência no serviço público, destaca que a atividade administrativa deve ser "exercida com presteza, perfeição e rendimento funcional, com resultados positivos para o serviço público e satisfatório atendimento das necessidades da coletividade."

O estudo possibilitou identificar as situações ocorridas no cotidiano da equipe da gerência de projetos tanto do ponto 
de vista organizacional quanto administrativo que poderiam ser otimizadas e tornadas mais eficientes. Paiva, Aragão \& Pereira, (2005) destacam que a mudança no perfil do colaborador, baseada no conhecimento, contribui para a evolução organizacional.

O uso da adaptação do Framework Scrum na GP, possibilitou ganhos que vão além da economicidade de custo, tempo e escopo (Veras, 2016), pois favoreceu a troca de experiências dos servidores do setor com os representantes das unidades beneficiadas. As etapas anteriormente comentadas convergiram para uma significativa redução de custos de material, consumo de energia elétrica, papel e tinta para impressora, além de tornar o projeto conhecido de toda equipe. Isso proporciona à gestão pública melhor efetividade e transparência nos gastos, podendo inclusive disponibilizar tais informações em seu site para que a população possa acompanhar. O resultado simplificado do uso da metodologia Scrum aplicada neste estudo pode ser observado no Quadro 5, que apresenta além da redução no tempo gasto na execução das atividades de elaboração do projeto, o percentual de redução em relação ao modelo atual de gestão.

Quadro 5 - Atividades desenvolvidas e seu tempo de execução com a implantação da adaptação do Scrum.

\begin{tabular}{|l|c|c|}
\hline \multicolumn{1}{|c|}{ Atividade } & $\begin{array}{c}\text { Tempo } \\
\text { (dias) }\end{array}$ & $\begin{array}{c}\text { Percentual de redução tempo gasto na } \\
\text { atividade em relação ao modo tradicional }\end{array}$ \\
\hline Levantamento da área de implantação & 1 a 2 & $0 \%$ \\
\hline $\begin{array}{l}\text { Aquisição de documentação que deverá } \\
\text { constar no projeto }\end{array}$ & 5 a 15 & $67 \%$ \\
\hline $\begin{array}{l}\text { Elaboração de projetos (topografia, } \\
\text { arquitetura, hidrossanitário, elétrico etc. }\end{array}$ & 10 a 30 & $57 \%$ \\
\hline Anuência dos órgãos externos & 5 a 15 & $75 \%$ \\
\hline Aprovação do órgão concedente & 10 a 30 & $67 \%$ \\
\hline Duração & 31 a 92 & $66 \%$ \\
\hline
\end{tabular}

Fonte: Autores.

\section{Considerações Finais}

Com a implantação da adaptação do Framework Scrum no setor GP obtivemos ganhos consideráveis de recursos de tempo, humanos e materiais.

Obteve-se uma economia de custos tendo em vista que anteriormente imprimia-se os projetos em vários momentos antes de sua conclusão e agora somente no final.

A equipe de trabalho reportou que houve um ganho na qualidade das atividades executadas, pois se trabalha menos com uma efetividade maior. Os membros das equipes se comunicam constantemente e uma tarefa é realizada apenas por um membro da equipe.

E finalmente, houve uma redução do tempo na elaboração de projetos em média de 112 dias, pois um projeto que antes levava em média 174 dias, hoje pode ser concluído em até 62 dias. Desta forma podemos concluir que a equipe de elaboração de projetos já amadureceu e enriqueceu muito o seu conhecimento técnico na elaboração de projetos.

Hoje os membros conseguem, preliminarmente, estimar o valor de um projeto, pois já possuem um valor do metro linear ou quadrado de uma obra, com isto a secretaria tende a se beneficiar com esta implantação, assim como a população, que terá a oportunidade de ser contemplada com um número maior de projetos, diminuído consideravelmente as falhas que muitas das vezes, tinham como consequência aditivos de valores ou de prazos influenciando na entrega das obras à população. Porém para que essa implantação seja mais eficaz ainda necessitamos que sejam contratados novos profissionais, assim como adquiridos novos equipamentos que os auxiliem na execução do seu trabalho diário na elaboração de projetos.

Considerando a dinâmica da administração pública, sugere-se que em trabalhos futuros seja avaliada a percepção dos 
representantes dos órgãos que tiveram projetos comtemplados e o usuário destes órgãos, quanto à efetividade do uso desta ferramenta no cumprimento das normas técnicas, otimização de recursos e minimização de eventuais adaptações após a aprovação dos projetos.

\section{Referências}

Bergamaschi, A. A. \& Zuchi, J. D. (2018). Gerenciamento de tempo com base em informação e metodologias ágeis. Revista Interface Tecnológica. v. 15(1).

Bomfin, D. F.; Nunes, P. C.; Hastenreiter, F. (2012). Gerenciamento de projetos segundo o guia PMBOK: desafios para os gestores. Revista de Gestão e Projetos, v. 3(3), 58-87.

Brasil. (1993). Lei n ${ }^{\circ}$ 8.666, de 21 de junho de 1993. Regulamenta o art. 37, inciso XXI, da Constituição Federal, institui normas para licitações e contratos da Administração Pública e dá outras providências. Diário Oficial da União, Brasília, DF, 22 jun. 1993. http://www.planalto.gov.br/ccivil_03/leis/18666cons.htm.

Camargo, K. G. A., Galegale, N. V., Azevedo, M. M. de, \& Neves, J. M. S. das. (2020). Estudo sobre associação de modelos de maturidade e metodologias ágeis. Research, Society and Development, 9(2), e115922169. https://doi.org/10.33448/rsd-v9i2.2169.

Coelho Ferreira, A. (2019). Ganhos e Melhorias com a Utilização de Modelos Híbridos na Gestão de Projetos de TI. Boletim do Gerenciamento, 6(6), 1-10. https://nppg.org.br/revistas/boletimdogerenciamento/article/view/157.

Conboy, K. (2009). Agility from first principles: Reconstructing the concept of agility in information systems development. Information systems research, 20(3), 329-354.

Cruz, F. (2018). Scrum e Agile em Projetos: guia completo. Rio de Janeiro: $2^{\text {a }}$ Ed. Editora Brasport,

Geraldi, J.; Maylor, H. \& Williams, T. (2011). Now, Let's Make it Really Complex (Complicated): a systematic review of the complexities of projects. International Journal of Operations \& Production Management, v. 31(9), 966-990.

Medeiros, L. (Org.). (2013). Princípios Básicos da Administração Pública. Poderes, Deveres, Direitos e Responsabilidades do Servidor. São Paulo: Universidade de São Paulo.

Melo, C. O.; Ferreira, G. R. M. (2010). Adoção de métodos ágeis em uma instituição pública de grande porte: um estudo de caso. Conference on Agile Methods. Agile Brazil 2010. São Paulo. http://ccsl.ime.usp.br/agilcoop/files/WBMA_Melo_e_Ferreira.pdf.

Mendonça, J.; Vieira, M. F.; Santos, T.; Santana, S. A. (2018). Implantação de Gestão Ágil na Engenharia Civil. Revista Eletrônica da Reunião Anual de Ciência-e_RAC. v. 8(1).

Oliveira, M. M. de. (2011). Como fazer projetos, relatórios, monografias, dissertações e teses. 5. Ed. Rio de Janeiro: Elsevier.

Paiva, S. B.; Aragão, P. O. R. de; Pereira, S. L. (2005). Gestão do Conhecimento em uma organização baseada em conhecimento: uma abordagem qualitativa. Produto \& Produção, v. 8(2), 37-56. http://www.seer.ufrgs.br/ProdutoProducao/article/view/3212.

PMI. (2017). Project Management Body of Knowledge Guide. Pennsylvania: Four Campus Boulevard.

Prodanov, C. C. \& Freitas, E. C. de. (2013). Metodologia do trabalho científico: Métodos e Técnicas da Pesquisa e do Trabalho Acadêmico. $2^{\text {a }}$. ed. Novo Hamburgo: Universidade Freevale.

Schwaber, K. \& Sutherland, J. (2017). Guia do Scrum: Um guia definitivo para o Scrum, as regras do Jogo. Califórnia, Creative Commons.

Silva, D. E. dos S.; Ingredy Souza, T. de; Camargo, T. (2013). Metodologias ágeis para o desenvolvimento de software: aplicação e o uso da metodologia Scrum em contraste ao modelo tradicional de gerenciamento de projetos. Revista Computação Aplicada. v. 2(1).

Silva, R. E. da \& Neto, J. S. (2015). Contratação do desenvolvimento ágil de software na administração pública federal: riscos e ações mitigadoras. Revista do Serviço Público Brasília 66(1), 97-120.

Stopa, G. R. \& Rachid, C. L. (2019). Scrum: metodologia ágil como ferramenta de gerenciamento de projetos. CES Revista. v. 33(1).

Veras, M. (2016). Gestão dinâmica de projetos: Life Cycle Canvas. Rio de Janeiro: Brasport. 